\title{
Cellular abnormalities in Autosomal Dominant Polycystic Kidney Disease (ADPKD) fibroblasts
}

\author{
S Moyes, , J Norman, PD Wilson \\ From First International Cilia in Development and Disease Scientific Conference (2012) \\ London, UK. 16-18 May 2012
}

\begin{abstract}
ADPKD is a common, monogenic disease in which aberrant polycystin (PC)-1 function leads to end-stage renal disease. Progressive tubular epithelial cyst enlargement is accompanied by variable amounts of tubulointerstitial fibrosis contributing to disease progression. Although ADPKD abnormalities have been studied in detail in cystic epithelia where PC-1 is localised in apical cilia and basal matrix-associated focal adhesions (FA), little is known about PC-1 or cilia in ADPKD fibroblasts. Previously we identified a hyperproliferation defect in ADPKD fibroblasts analogous to cystic epithelia. Here we use matrixadhesion, Western blot and immunolocalisation in human "early"-stage, pre-dialysis (E-), and end-stage (ES-) ADPKD versus normal (N) tissues and cells to further characterise differences between these fibroblasts. In vivo, stage-dependent increases in aSMA-containing fibroblasts, interstitial collagen deposition and cystic-epithelial TGF $\beta$ content were seen in ADPKD kidneys together with focal interstitial PC-1 expression. In vitro primary cultures of N, E- and ES-ADPKD fibroblasts showed stage-related increases in matrix adhesion; increased spreading; upregulation and phosphorylation of FA proteins, FAK and paxillin. $\alpha$ SMA was absent in $\mathrm{N}$ but markedly upregulated in ES-ADPKD fibroblasts and incorporated into stress fibres. All types of fibroblasts produced cilia; cilia length decreased with disease stage. Fibroblasts also expressed PC-1 but only $\mathrm{N}$ expressed full-length $\mathrm{PC}-1$ (460kD) and the $\sim 250 \mathrm{kD}$ fragment. Several smaller fragments (30-100kD) were detected in ADPKD, mostly decreasing with disease stage. Interestingly, the putative C-terminal $\sim 30 \mathrm{kD}$ PC-1 fragment was downregulated in ADPKD fibroblasts which also showed reduced nuclear PC-1 staining. We conclude that abnormalities in $\mathrm{PC}-1$ and cilia may play important roles in the ADPKD fibroblast phenotype.
\end{abstract}

\footnotetext{
* Correspondence: s.moyes@ucl.ac.uk

UCL Centre for Nephrology, UCL Medical School, London, UK
}

Published: 16 November 2012

doi:10.1186/2046-2530-1-S1-P95

Cite this article as: Moyes et al:: Cellular abnormalities in Autosomal Dominant Polycystic Kidney Disease (ADPKD) fibroblasts. Cilia 2012 1(Suppl 1):P95.
Submit your next manuscript to BioMed Central and take full advantage of:

- Convenient online submission

- Thorough peer review

- No space constraints or color figure charges

- Immediate publication on acceptance

- Inclusion in PubMed, CAS, Scopus and Google Scholar

- Research which is freely available for redistribution

Submit your manuscript at www.biomedcentral.com/submit
C Biomed Central 